\title{
Article \\ Picosecond Q-Switched 1064/532 nm Laser in Tattoo Removal: Our Single Center Experience
}

\author{
Luigi Bennardo $1,2,+\left(\mathbb{D}\right.$, Giovanni Cannarozzo ${ }^{3,+}$, Federica Tamburi $^{2}$, Cataldo Patruno ${ }^{2}$, , Eugenio Provenzano ${ }^{1}$ \\ and Steven Paul Nisticò ${ }^{2, *}$ \\ 1 Unit of Dermatology, Mariano Santo Hospital, 87100 Cosenza, Italy; luigibennardo10@gmail.com (L.B.); \\ eprovenzano0@gmail.com (E.P.) \\ 2 Department of Health Sciences, Magna Graecia University, 88100 Catanzaro, Italy; \\ federica.tamburi@gmail.com (F.T.); cataldopatruno@libero.it (C.P.) \\ 3 Unit of Dermatology, Tor Vergata University, 00100 Rome, Italy; drcannarozzo@gmail.com \\ * Correspondence: steven.nistico@gmail.com; Tel.: +39-096-1364-7195 \\ + These authors contributed equally to the paper.
}

Citation: Bennardo, L.; Cannarozzo,

G.; Tamburi, F.; Patruno, C.;

Provenzano, E.; Nisticò, S.P.

Picosecond Q-Switched 1064/532 nm Laser in Tattoo Removal: Our Single Center Experience. Appl. Sci. 2021, 11, 9712. https://doi.org/10.3390/ app11209712

Academic Editor: Cristian FOCSA

Received: 11 September 2021

Accepted: 14 October 2021

Published: 18 October 2021

Publisher's Note: MDPI stays neutral with regard to jurisdictional claims in published maps and institutional affiliations.

Copyright: (c) 2021 by the authors. Licensee MDPI, Basel, Switzerland. This article is an open access article distributed under the terms and conditions of the Creative Commons Attribution (CC BY) license (https:// creativecommons.org/licenses/by/ $4.0 /)$.

\begin{abstract}
Background: Tattoo removal is becoming increasingly popular, and Q-switched lasers represent the gold standard in the treatment of this condition. In this study, we report our experience with a new Q-switched picosecond laser device, evaluating its effectiveness and safety. Methods: A total of 34 patients asking for tattoo removal were consecutively enrolled in this open study. The clinicians decided on operating settings based on the Fitzpatrick phototype, the type of tattoo, and the tattoo location. A maximum of seven sessions, with a minimum interval of eight weeks between each session, were performed. At the six month follow-up visit following the last treatment session, patient satisfaction was assessed using a visual analogue scale and two dermatologists evaluated the aesthetic outcome based on pictures taken before and after treatment. Results: A total of 34 patients were included and analyzed: 17 females (50\%) and 17 males (50\%). The mean patient age was $43.6 \pm 11$ years. Participants' Fitzpatrick skin type ranged from II to IV. The mean number of treatment sessions performed was $3.3 \pm 2.0$ per patient. Over $40 \%$ of patients showed complete removal of the tattoo, with most of the patients indicating satisfaction with the treatment. Conclusions: The Q-switched 1064/532 nm laser may be considered the gold standard treatment for tattoo removal. Picosecond pulses seem to guarantee fewer sessions and excellent results when compared to other laser systems in tattoo removal.
\end{abstract}

Keywords: picosecond laser; Q-switched laser; tattoo removal

\section{Introduction}

Tattoos are becoming more and more diffuse in the general population as a sign of individualism [1]. Tattoo removal is a new expanding field in cosmetic dermatology [2]. Although various procedures have been suggested, such as chemical ablation and surgery, lasers are currently considered the gold standard procedure [3]. To remove tattoos, dermatologists have used electrocution, grinding, freezing, and skin grafting, but the results have not been satisfactory. In the 1960s, with the advent of laser technology, Laub et al. introduced the use of ruby lasers to remove human tattoos, and the applications of various laser technologies on tattoo treatments emerged gradually from then on to using ablative lasers, such as $\mathrm{CO}_{2}$ or Erbium-based devices [4-6].

However, these lasers may induce superficial tissue destruction. Therefore, $\mathrm{CO}_{2}$ lasers may be considered as a standard treatment for benign, nodular, superficial, small lesions. When used in fractional mode, this laser seems to be effective in the treatment of facial aging and other conditions [7-10]. When used for tattoo removal, the risk of scarring with these devices is considerable $[7,8]$. Therefore, devices targeting unique chromophores 
may represent a better option [11]. Nd YAG lasers, acting at a 1064/532 nm wavelength, effectively manage this condition [12].

Furthermore, recent reports indicate that lasers releasing a huge quantity of energy in a fraction of a second may act specifically on tattoos, leaving the adjacent skin unarmed [13]. Picosecond pulses seem to guarantee higher effectiveness than longer nanosecond pulses, thus reducing the number of treatment sessions and improving cosmetic outcomes [14,15]. This paper estimates the safeness and efficacy of tattoo removal with a picosecond Qswitched 1064/532 nm laser.

\section{Materials and Methods}

Outpatients seeking tattoo removal from 1 August 2019 to 30 December 2020 at Magna Graecia University's Dermatology Unit (Catanzaro, Italy) were included in our study. Patients suffering from light hypersensitivity, or taking drugs capable of increasing it, were excluded from the study. Further, patients taking gold-based medications, immunosuppressants, and/or anticoagulants, those who were pregnant, those previously affected by skin malignancies, those who had experienced strong sun exposure within the previous three weeks, those previously treated with other tattoo removal or exfoliation procedures, and those suffering from diseases associated with the Koebner phenomenon were excluded from the study. All patients signed an informed consent regarding the possible side effects related to the medical procedure.

Participants have been treated with a picosecond Q-switched 1064/532 nm laser system (Pico, Deka M.E.L.A., Calenzano, Italy), capable of obtaining selective photothermolysis of the tattoo ink, with minimal injury to the adjacent skin. The treatment parameters were as follows: 450 picoseconds (ps) at $1064 \mathrm{~nm}$ and $370 \mathrm{ps}$ at $532 \mathrm{~nm}$; up to $5 \mathrm{~J} / \mathrm{cm}^{2}$ at $1064 \mathrm{~nm}$ for black and blue pigments; and up to $3 \mathrm{~J} / \mathrm{cm}^{2}$ at $532 \mathrm{~nm}$ for all other colors. Treated tattoos were stratified based on their characteristics and anatomical location, using a previously proposed scale [16] (Table 1).

Table 1. Tattoo classes identified and included in the study.

\begin{tabular}{cc}
\hline Group & Description \\
\hline Dark Tattoos & $\begin{array}{c}\text { Qualified professionals tattooed the patient } \\
\text { using mostly black-colored ink }\end{array}$ \\
\hline Red Tattoos & $\begin{array}{c}\text { Qualified professionals tattooed the patient } \\
\text { using mostly red-colored ink }\end{array}$ \\
\hline Mixed-Color Tattoos & $\begin{array}{c}\text { Qualified professionals tattooed the patient } \\
\text { using a variety of colors }\end{array}$ \\
\hline Amateur & Unqualified professionals tattooed the patient \\
\hline Medical & Usually blue superficial tattoos before \\
radiotherapy
\end{tabular}

Tattoos simultaneously displaying multiple colors were treated with both wavelengths, using the appropriate wavelength for each area. Up to seven sessions have been performed to provide the best possible cosmetic result.

An 8-week interval between each laser treatment up to the fourth session was performed; the interval was then increased to 12 weeks for subsequent sessions. Patients' satisfaction was the primary endpoint. A 6-month follow-up visit was scheduled after the last laser treatment.

Before the first treatment, a photographic evaluation was performed and repeated at the 6-month follow-up. Pictures were taken with the same device (Nikon 5600d, Nikon Corporation, Minato City, Tokyo, Japan), parameters, settings, and ambient light. 
The photographs were evaluated by 2 dermatologists, who scored the tattoo removal using a 5-point scale $(0-20 \%$ removal $=0 ; 20-40 \%$ removal $=1 ; 40-60 \%$ removal $=2 ; 60-80 \%$ removal $=3 ; 80-100 \%$ removal $=4)$.

A visual analogue scale (VAS) ranging from 1 to 10 was administered to the patients at the 6-month follow-up to measure patient satisfaction (Figures 1-5).

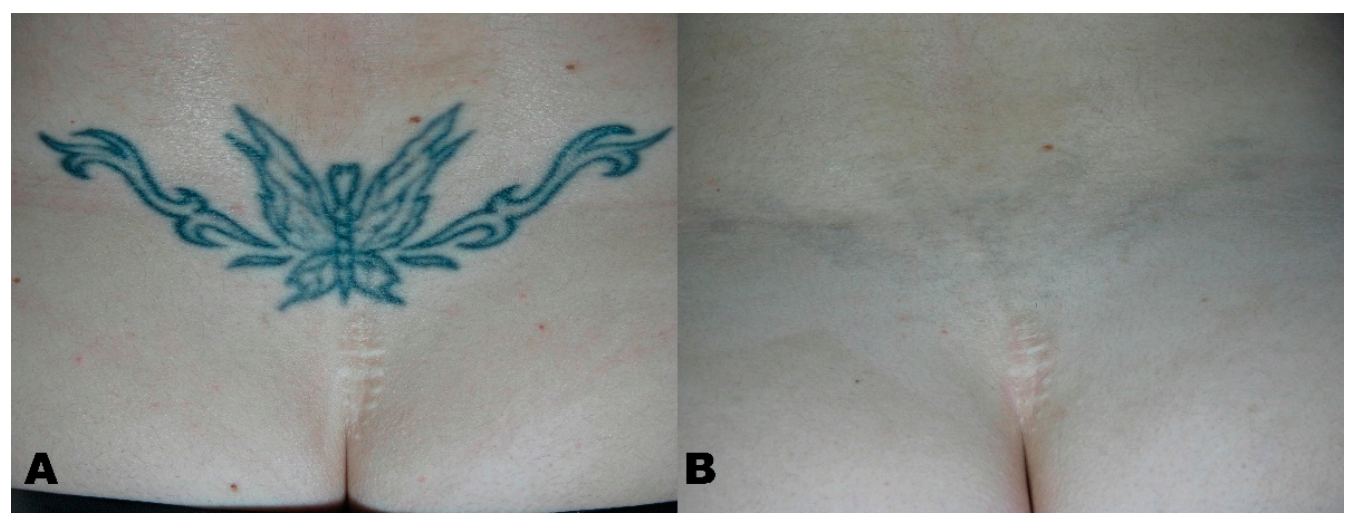

Figure 1. (A) Picture before starting tattoo removal treatment, and (B) the same region at the 6-month follow-up, after all tattoo removal sessions had been completed.

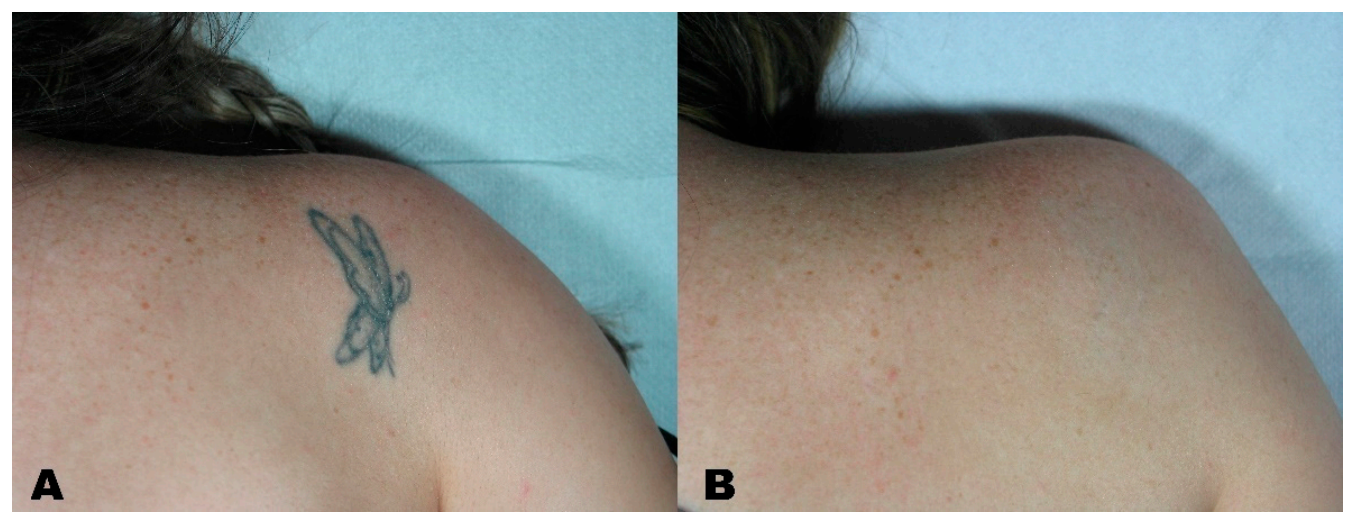

Figure 2. (A) Picture before starting tattoo removal treatment, and (B) the same region at the 6-month follow-up, after all tattoo removal sessions had been completed.

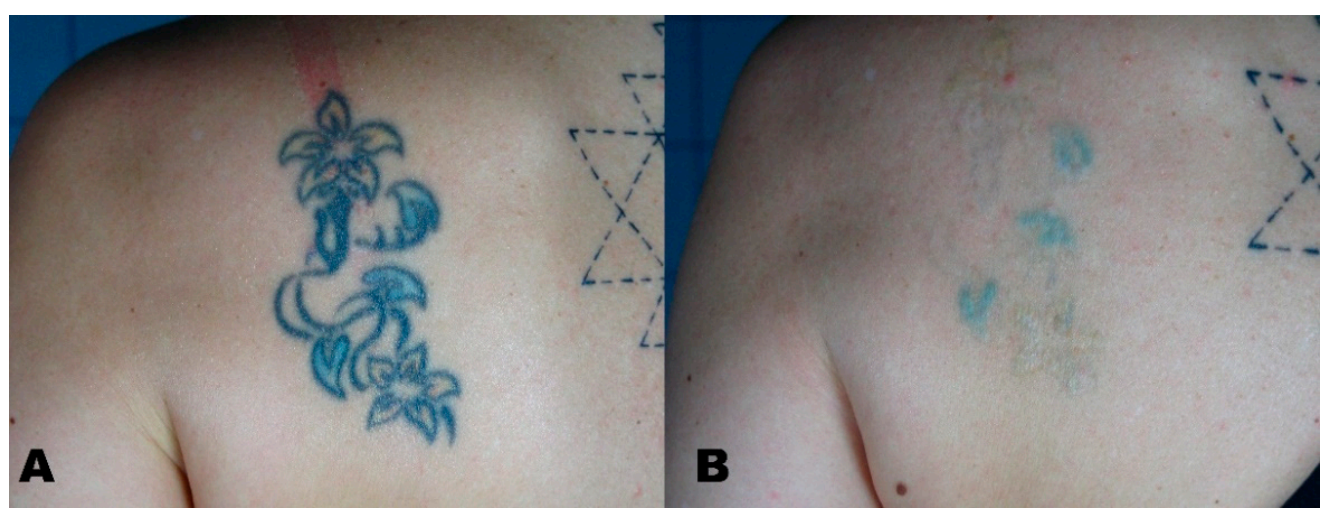

Figure 3. (A) Picture before starting tattoo removal treatment, and (B) the same region at the 6-month follow-up, after all tattoo removal sessions had been completed. 


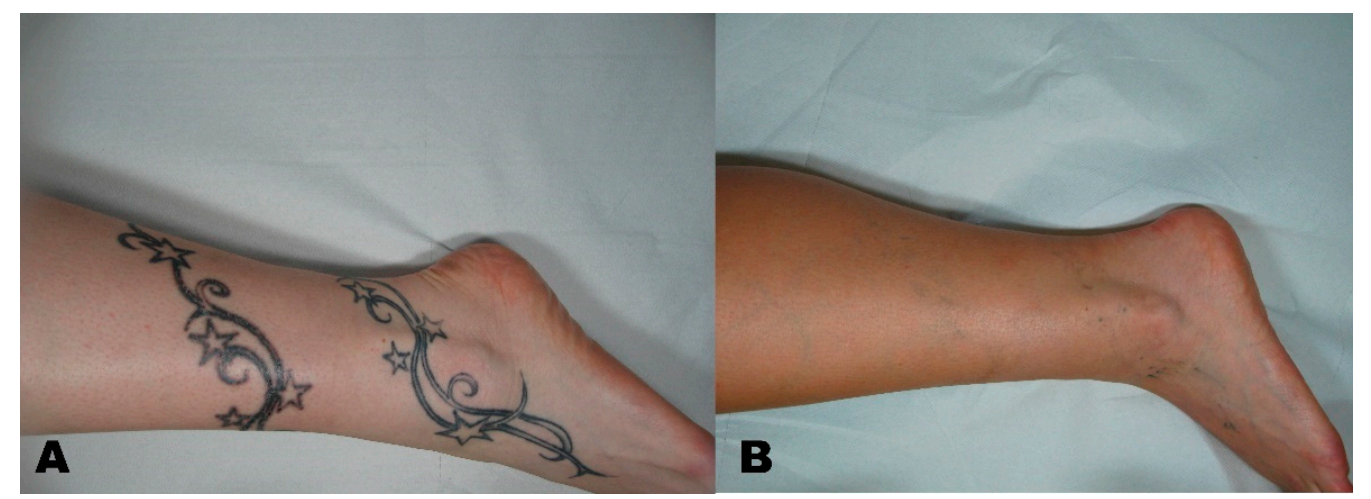

Figure 4. (A) Picture before starting tattoo removal treatment, and (B) the same region at the 6-month follow-up, after all tattoo removal sessions had been completed.

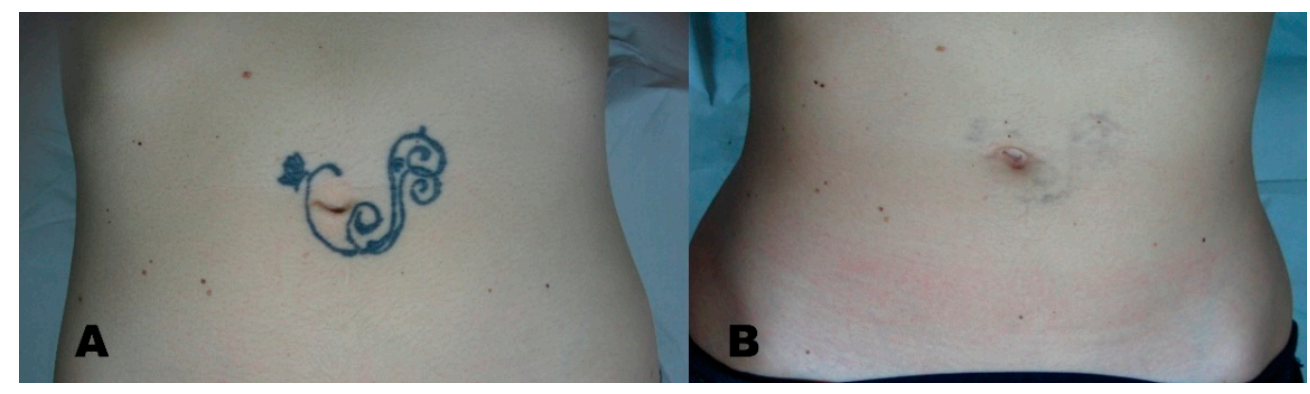

Figure 5. (A) Picture before starting tattoo removal treatment, and (B) the same region at the 6-month follow-up, after all tattoo removal sessions had been completed.

Data analyses (mean, standard deviations, etc.) were performed using Statistica 14.0 (TIBCO Software, Palo Alto, CA, USA).

\section{Results}

In this retrospective study, 34 patients were included and analyzed: 17 females $(50 \%)$ and 17 males $(50 \%)$. The mean age was $43.6 \pm 11$ years. Participants' skin ranged from Fitzpatrick type II to IV; in detail, 10 individuals $(29.4 \%)$ were type II, $13(38.2 \%)$ were type III, and $11(32.4 \%)$ were type IV. Most tattoos were professionally tattooed ( $n=15$, $44.1 \%)$ and intensely colored in dark, red, or mixed tonalities; amateur tattoos $(n=9$, $26.5 \%)$ formed another relevant subgroup, followed by cosmetic $(n=4,11.8 \%)$, traumatic $(n=4,11.8 \%)$, and medical tattoos $(2,5.9 \%)$. The location of the tattoos spread from the head to the extremities, with a slight prevalence in upper trunk/shoulder $(n=9,26.5 \%)$ and a homogeneous rate among the lower trunk/upper leg, lower arm/leg, and face/head sites $(n=8,23.5 \%$ in each subgroup. Patients' characteristics are reported in Table 2.

Performed sessions ranged from 1 to 7 , with a mean of $3.3 \pm 2.0$ required sessions (Table 3). No differences in the number of sessions were noted after considering Fitzpatrick phototypes, while some differences could be observed based on tattoo location or subgroup classes (Table 4): professional andmixed colors tattoos required an higher number of sessions, as lesions interesting the extremities, while cosmetic, medical and, in general, face tattoos could be removed in fewer sessions. All included patients had a dermatologistevaluated tattoo removal rate of $60 \%$ or higher, i.e., a score of $>3$ (Table 3), while 4 out of 10 participants $(41.2 \%)$ scored a complete $(80-100 \%)$ removal rate. 
Table 2. Demographic data of included patients.

\begin{tabular}{cc}
\hline Patient No. & 34 \\
Female (\%) & $17(50 \%)$ \\
Male (\%) & $17(50 \%)$ \\
Mean age \pm SD [years] & $43.6 \pm 11$ \\
Age range [years] & $26-58$ \\
Fitzpatrick phototype: & \\
II (\%) & $10(29.4 \%)$ \\
III (\%) & $13(38.2 \%)$ \\
IV (\%) & $11(32.4 \%)$ \\
Tattoo Type: 1 & \\
Dark tattoos (\%) & $15(44.1 \%)$ \\
Red tattoos (\%) & $7(20.6 \%)$ \\
Mixed-color group (\%) & $6(17.6 \%)$ \\
Amateur (\%) & $2(5.9 \%)$ \\
Medical (\%) $\%$ which: & $9(26.5 \%)$ \\
Traumatic (\%) & $2(5.9 \%)$ \\
Cosmetic (\%) & $4(11.8 \%)$ \\
Tattoo location: & $4(11.8 \%)$ \\
Face/head (\%) & \\
Upper trunk/shoulder (\%) & $8(23.5 \%)$ \\
Lower trunk/upper leg (\%) & $9(26.5 \%)$ \\
Lower arm/leg (\%) & $8(23.5 \%)$ \\
Wrist/hand/ankle/foot (\%) & $8(23.5 \%)$ \\
\end{tabular}

${ }^{1}$ see Table 1 for class specifications.

Table 3. Tattoo removal scores.

\begin{tabular}{cccc}
\hline & No. Patients (\%) & Mean No. Sessions \pm SD & No. Sessions Range \\
\hline Total & $34(100 \%)$ & $3.3 \pm 2.0$ & $1-7$ \\
Tattoo removal scores & & & \\
$3(60-80 \%)$ & $20(58.8 \%)$ & $3.3 \pm 1.9$ & $1-6$ \\
$4(80-100 \%)$ & $14(41.2 \%)$ & $3.3 \pm 2.3$ & $1-7$ \\
\hline
\end{tabular}

Table 4. Tattoo removal scores and clinical characteristics among different subgroups.

\begin{tabular}{|c|c|c|c|c|}
\hline & Mean No. Sessions \pm SD & No. Sessions Range & $\begin{array}{c}\text { Tattoo Removal Score } 3 \\
(60-80 \%)[n ; \%]\end{array}$ & $\begin{array}{l}\text { Tattoo Removal Score } 4 \\
(80-100 \%)[n ; \%]\end{array}$ \\
\hline \multicolumn{5}{|l|}{ Fitzpatrick phototype: } \\
\hline II & $3.6 \pm 2.0$ & $1-6$ & $7(70 \%)$ & $3(30 \%)$ \\
\hline III & $3.0 \pm 2.1$ & $1-7$ & $5(38.5 \%)$ & $8(61.5 \%)$ \\
\hline IV & $3.4 \pm 2.2$ & $1-7$ & $8(72.7 \%)$ & $3(27.3 \%)$ \\
\hline \multicolumn{5}{|l|}{ Tattoo Type: } \\
\hline \multicolumn{5}{|l|}{ Professional: } \\
\hline Dark tattoos & $5.0 \pm 0.8$ & $4-6$ & $5(71.4 \%)$ & $2(28.6 \%)$ \\
\hline Red tattoos & $5.3 \pm 0.8$ & $4-6$ & $4(66.7 \%)$ & $2(33.3 \%)$ \\
\hline Mixed-color tattoos & $7.0 \pm 0.0$ & 7 & $0(0 \%)$ & $2(100 \%)$ \\
\hline Amateur & $1.7 \pm 0.5$ & $1-2$ & $6(66.7 \%)$ & $3(33.3 \%)$ \\
\hline Medical & $1.5 \pm 0.7$ & $1-2$ & $1(50 \%)$ & $1(50 \%)$ \\
\hline Traumatic & $1.8 \pm 0.5$ & $1-2$ & $2(50 \%)$ & $2(50 \%)$ \\
\hline Cosmetic & $1.5 \pm 0.6$ & $1-2$ & $2(50 \%)$ & $2(50 \%)$ \\
\hline \multicolumn{5}{|l|}{ Tattoo location: } \\
\hline Face/head & $1.6 \pm 0.5$ & $1-2$ & $4(50 \%)$ & $4(50 \%)$ \\
\hline Upper trunk/shoulder & $3.3 \pm 1.7$ & $1-6$ & $6(66.7 \%)$ & $3(33.3 \%)$ \\
\hline Lower trunk/upper leg & $4.9 \pm 1.9$ & $2-7$ & $5(62.5 \%)$ & $3(37.5 \%)$ \\
\hline Lower arm/leg & $3.5 \pm 2.5$ & $1-7$ & $4(50 \%)$ & $4(50 \%)$ \\
\hline Wrist/hand/ankle/foot & $2(n=1)$ & $2(n=1)$ & $1(100 \%)$ & $0(0 \%)$ \\
\hline
\end{tabular}

The best outcomes were observed among phototype III patients (score $=4$ in $61.5 \%$ ), while for patients in phototypes II and IV, only about one-third of cases ( $30 \%$ for phototype II and $27.3 \%$ for phototype IV) reached $80-100 \%$ tattoo removal. Though there were limited cases, and a non-homogenous number of cases in different subgroups, the collected data allowed for some qualitative observations. Considering medical, traumatic, and cosmetic 
tattoos, half of the treated cases were assessed with a score of four, against just one-third $(33.3 \%)$ of the cases in the amateur group. As far as professional tattoos were concerned, a range of $28.6-33.3 \%$ of cases reached the top score for removal-except for the mixed color subgroup, where both cases were removed at rates of $80-100 \%$ (Table 4). All participants showed reasonable satisfaction after laser treatment, with an average visual analogue scale score of $7.26 \pm 1.40$.

No severe side effects were reported. No patients left the study. In three cases, a final "ghost effect" was reported; six participants developed petechiae after treatment and were medicated with an occlusive dressing, hydrolytic enzymes, and antibiotics, with the disappearance of the vasculare manifestations in one to two weeks.

\section{Discussion}

The QS Nd: YAG laser is reported as the optimal tattoo removal device because it can obtain excellent cosmetic results with minimal skin damage, low scarring risk, and low incidence of hypopigmentation $[17,18]$. A two-month interval between sessions permits the removal of tattoo pigmented particles via the phagocytic cells, and it is necessary before carrying out any other session or procedure $[19,20]$. Red ink is more frequently associated with long-term reactions, including granulomatous and pseudolymphomatous phenomena or morphea-like lesions and vasculitis. The exacerbation of preexisting psoriasis, atopic dermatitis, and pyoderma gangrenosum may occur after tattooing [21]. Preoperative assessment must include the evaluation of scars under the tattoo, as removing the pigment may expose them [22]. Scars exposed after tattoo removal may then be treated as all other marks are: with a pulsed dye laser device or with some of the new lasers that target connective tissue. The results, however, may not be always cosmetically acceptable $[23,24]$ (de las alas, cannarozzo). Q-Switched lasers have been on the market for numerous years; the technology and pulse duration have been modified during this time, and the picosecond pulsed laser is considered the gold standard in tattoo removal $[25,26]$. Even if they can be considered the latest technological finding in tattoo removal, Q-switched picosecond lasers cannot remove professional tattoos altogether; complete clearance was only reported in about $30 \%$ of participants. Patients must be informed of the possibility of residual pigmentation after treatment, especially in the case of professional tattoos [27]. The risk of adverse events, such as hyperpigmentation, hypopigmentation, and skin darkening, must be communicated to patients [28,29]. Colored tattoos respond poorly to removal-especially when the pigment is yellow or green-even when using other types of Q-switched lasers, such as alexandrite $(755 \mathrm{~nm})$. Moreover, poor responses to treatment may be due to larger tattoo dimensions (larger than $30 \mathrm{~cm}$ ), pigment density, anatomical sites (lower extremities), and the age of the tattoo (three or more years old) [30]. Our experience suggests that picosecond laser treatment may help reduce the mean number of sessions and associated side effects, with cosmetic results similar to nanosecond pulse devices. However, these results may be biased because picosecond sources are often used for harder-to-treat tattoos, such as professional tattoos with mixed colors. Photoacoustic imaging may be useful as a clinical adjunct for the objective preoperative evaluation of tattoos and potentially as a guide/monitor for laser-based tattoo removal procedures [31].

\section{Conclusions}

The exact mechanisms of laser-assisted tattoo fragmentation are hardly known. Different factors, such as short and intense laser pulses, non-linear effects of light, and nonlinear thermal properties in tattoo particles may play a crucial role. Q-switched laser treatments may be considered the gold-standard therapy. In this study, professional mixed colors tattoos and tattoos on the lower limbs were harder to treat. Conversely, amateur and facial tattoos were easier to remove. Theoretical considerations assumed that shorter pulse durations allow for more effective fragmentation of tattoo particles, and initial studies affirm the effectiveness of picosecond pulses in tattoo treatment, with a reduction in pain and side effects $[27,30]$. In our experience, lasers using picosecond pulses seem to be more effective 
than the ones that use nanosecond pulses. Picosecond lasers may achieve a satisfactory result with fewer sessions and side effects, even if the improvement in cosmetic results does not seem statistically significant when compared to nanosecond lasers.

A prospective study with a larger number of participants and a randomized trial comparing picosecond and nanosecond laser sources would help to better analyze all the possible risks related to treatment and confirm the results we described in this study.

Author Contributions: Conceptualization, G.C. and L.B.; methodology, S.P.N.; software, C.P.; validation, S.P.N. and E.P.; investigation, G.C.; writing-original draft preparation, G.C. and L.B.; writing-review and editing, S.P.N. and L.B.; supervision, S.P.N. and F.T. All authors have read and agreed to the published version of the manuscript.

Funding: This research received no external funding.

Institutional Review Board Statement: The study was conducted following the Declaration of Helsinki's guidelines, and approved by the Institutional Review Board of Calabria Centro (protocol code 000373/2019; date of approval, 17 December 2019).

Informed Consent Statement: Informed consent was obtained from all subjects involved in the study.

Data Availability Statement: Data available following reasonable requests to the corresponding author.

Conflicts of Interest: The authors declare no conflict of interest.

\section{References}

1. Witkoś, J.; Hartman-Petrycka, M. Gender Differences in Subjective Pain Perception during and after Tattooing. Int. J. Environ. Res. Public Health 2020, 17, 9466. [CrossRef] [PubMed]

2. Kluger, N.; Misery, L.; Seité, S.; Taieb, C. Regrets after tattooing and tattoo removal in the general population of France. J. Eur. Acad. Dermatol. Venereol. 2019, 33, e157-e159. [CrossRef] [PubMed]

3. Zhitny, V.P.; Iftekhar, N. Tattoo Removal: A Practice from Ancient Times. Dermatology 2020, 236, 390-392. [CrossRef] [PubMed]

4. Qu, Y.; Wang, L.; Zhou, P.; Zhang, W. Efficient Picosecond Laser for Tattoo Removal in Rat Models. Med. Sci. Monit. 2020, 26, e924583. [CrossRef] [PubMed]

5. Laub, D.R.; Yules, R.B.; Arras, M.; Murray, D.E.; Crowley, L.; Chase, R.A. Preliminary histopathological observation of Q-switched ruby laser radiation on dermal tattoo pigment in man. J. Surg. Res. 1968, 8, 220-224. [CrossRef]

6. Kim, M.; Park, S.; Lee, H.U.; Kang, H.W. Quantitative Monitoring of Tattoo Contrast Variations after 755-nm Laser Treatments in In Vivo Tattoo Models. Sensors 2020, 20, 285. [CrossRef]

7. Mercuri, S.R.; Brianti, P.; Dattola, A.; Bennardo, L.; Silvestri, M.; Schipani, G.; Nisticò, S.P. $\mathrm{CO}_{2}$ laser and photodynamic therapy: Study of efficacy in periocular BCC. Dermatol. Ther. 2018, 31, e12616. [CrossRef]

8. Cannarozzo, G.; Bennardo, L.; Negosanti, F.; Nisticò, S.P. $\mathrm{CO}_{2}$ Laser Treatment in Idiopathic Scrotal Calcinosis: A Case Series. J. Lasers Med. Sci. 2020, 11, 500-501. [CrossRef]

9. Nistico, S.P.; Silvestri, M.; Zingoni, T.; Tamburi, F.; Bennardo, L.; Cannarozzo, G. Combination of Fractional CO $\mathrm{CO}_{2}$ Laser and Rhodamine-Intense Pulsed Light in Facial Rejuvenation: A Randomized Controlled Trial. Photobiomodul. Photomed. Laser Surg. 2021, 39, 113-117. [CrossRef]

10. Lodi, G.; Sannino, M.; Caterino, P.; Cannarozzo, G.; Bennardo, L.; Nisticò, S.P. Fractional $\mathrm{CO}_{2}$ laser-assisted topical rifamycin drug delivery in the treatment of pediatric cutaneous leishmaniasis. Pediatr. Dermatol. 2021, 38, 717-720. [CrossRef] [PubMed]

11. Lajevardi, V.; Mahmoudi, H.; Karimi, F.; Kalantari, Y.; Etesami, I. Comparing QS Nd:YAG laser alone with its combination with fractional ablative Er:YAG in tattoo removal. J. Cosmet. Dermatol. 2021. [CrossRef]

12. Kurniadi, I.; Tabri, F.; Madjid, A.; Anwar, A.I.; Widita, W. Laser tattoo removal: Fundamental principles and practical approach. Dermatol. Ther. 2021, 34, e14418. [CrossRef] [PubMed]

13. Goldust, M.; Wollina, U. Periorbital Hyperpigmentation-Dark Circles under the Eyes; Treatment Suggestions and Combining Procedures. Cosmetics 2021, 8, 26. [CrossRef]

14. Del Duca, E.; Zingoni, T.; Bennardo, L.; Di Raimondo, C.; Garofalo, V.; Sannino, M.; Petrini, N.; Cannarozzo, G.; Bianchi, L.; Nisticò, S.P. Long-Term Follow-Up for Q-Switched Nd:YAG Treatment of Nevus of Ota: Are High Number of Treatments Really Required? A Case Report. Photobiomodul. Photomed. Laser Surg. 2021, 39, 137-140. [CrossRef] [PubMed]

15. Cannarozzo, G.; Negosanti, F.; Sannino, M.; Santoli, M.; Bennardo, L.; Banzola, N.; Negosanti, L.; Nisticò, S.P. Q-switched Nd:YAG laser for cosmetic tattoo removal. Dermatol. Ther. 2019, 32, e13042. [CrossRef]

16. Kirby, W.; Desai, A.; Desai, T. The Kirby-Desai Scale: A proposed scale to assess tattoo removal treatments. J. Clin. Aesthet. Dermatol. 2009, 2, 32-37. [PubMed]

17. Kato, H.; Doi, K.; Kanayama, K.; Araki, J.; Nakatsukasa, S.; Chi, D.; Mori, M.; Fuse, Y.; Sakae, Y.; Uozumi, T. Combination of Dual Wavelength Picosecond and Nanosecond Pulse Width Neodymium-Doped Yttrium-Aluminum-Garnet Lasers for Tattoo Removal. Lasers Surg. Med. 2020, 52, 515-522. [CrossRef] 
18. Lorgeou, A.; Perrillat, Y.; Gral, N.; Lagrange, S.; Lacour, J.P.; Passeron, T. Comparison of two picosecond lasers to a nanosecond laser for treating tattoos: A prospective randomized study on 49 patients. J. Eur. Acad. Dermatol. Venereol. 2018, 32, 265-270. [CrossRef]

19. Cannarozzo, G.; Nisticò, S.P.; Zappia, E.; Del Duca, E.; Provenzano, E.; Patruno, C.; Negosanti, F.; Sannino, M.; Bennardo, L. Q-Switched 1064/532 nm Laser with Nanosecond Pulse in Tattoo Treatment: A Double-Center Retrospective Study. Life 2021, 11, 699. [CrossRef]

20. Karsai, S. Removal of Tattoos by Q-Switched Nanosecond Lasers. Curr. Probl. Dermatol. 2017, 52, 105-112. [CrossRef]

21. Islam, P.S.; Chang, C.; Selmi, C.; Generali, E.; Huntley, A.; Teuber, S.S.; Gershwin, M.E. Medical Complications of Tattoos: A Comprehensive Review. Clin. Rev. Allergy Immunol. 2016, 50, 273-286. [CrossRef] [PubMed]

22. Pinto, F.; Große-Büning, S.; Karsai, S.; Weiß, C.; Bäumler, W.; Hammes, S.; Felcht, M.; Raulin, C. Neodymium-doped yttrium aluminium garnet (Nd:YAG) 1064-nm picosecond laser vs. Nd:YAG 1064-nm nanosecond laser in tattoo removal: A randomized controlledsingle-blind clinical trial. Br. J. Dermatol. 2017, 176, 457-464. [CrossRef] [PubMed]

23. De las Alas, J.M.; Siripunvarapon, A.H.; Dofitas, B.L. Pulsed dye laser for the treatment of keloid and hypertrophic scars: A systematic review. Expert Rev. Med. Devices 2012, 9, 641-650. [CrossRef] [PubMed]

24. Cannarozzo, G.; Silvestri, M.; Tamburi, F.; Sicilia, C.; Del Duca, E.; Scali, E.; Bennardo, L.; Nisticò, S. A new 675-nm laser device in the treatment of acne scars: An observational study. Lasers Med. Sci. 2021, 36, 227-231. [CrossRef] [PubMed]

25. Naga, L.I.; Alster, T.S. Laser Tattoo Removal: An Update. Am. J. Clin. Dermatol. 2017, 18, 59-65. [CrossRef] [PubMed]

26. Serup, J.; Bäumler, W. Guide to Treatment of Tattoo Complications and Tattoo Removal. Curr. Probl. Dermatol. 2017, 52, 132-138. [CrossRef]

27. Hsu, V.M.; Aldahan, A.S.; Mlacker, S.; Shah, V.V.; Nouri, K. The picosecond laser for tattoo removal. Lasers Med. Sci. 2016, 31, 1733-1737. [CrossRef]

28. Hutton Carlsen, K.; Esmann, J.; Serup, J. Tattoo removal by Q-switched yttrium aluminium garnet laser: Client satisfaction. J. Eur. Acad. Dermatol. Venereol. 2017, 31, 904-909. [CrossRef]

29. Silvestri, M.; Bennardo, L.; Zappia, E.; Tamburi, F.; Cameli, N.; Cannarozzo, G.; Nisticò, S.P. Q-Switched 1064/532 nm Laser with Picosecond Pulse to Treat Benign Hyperpigmentations: A Single-Center Retrospective Study. Appl. Sci. 2021, 11, 7478. [CrossRef]

30. Pedrelli, V.; Azzopardi, E.; Azzopardi, E.; Tretti Clementoni, M. Picosecond laser versus historical responses to Q-switched lasers for tattoo treatment. J. Cosmet. Laser Ther. 2020, 22, 210-214. [CrossRef]

31. Bolookat, E.R.; Rich, L.J.; Paragh, G.; Colegio, O.R.; Singh, A.K.; Seshadri, M. Photoacoustic Imaging of Tattoo Inks: Phantom and Clinical Evaluation. Appl. Sci. 2020, 10, 1024. [CrossRef] [PubMed] 